\title{
Biological functions and role of CCN1/Cyr61 in embryogenesis and tumorigenesis in the female reproductive system (Review)
}

\author{
RUI YANG, YING CHEN and DAOZHEN CHEN
}

Wuxi Maternity and Child Health Care Hospital Affiliated to Nanjing Medical University, Wuxi, Jiangsu 214002, P.R. China

Received December 13, 2016; Accepted September 18, 2017

DOI: $10.3892 / \mathrm{mmr} .2017 .7880$

\begin{abstract}
Cysteine-rich angiogenic inducer 61 (CCN1/Cyr61) is a prompt response transcription product activated by growth factors. As a member of the CCN family, it mediates cell survival, proliferation, differentiation, migration, adhesion and synthesis of the extracellular matrix by binding directly to the integrins and heparin sulfate proteoglycans or activating multiple signaling transduction pathways. It has previously been demonstrated that CCN1/Cyr61 exhibits an important role in the female reproductive system during embryogenesis and tumorigenesis. However, the functions of CCN1/Cyr61 in the female reproductive system have not been systematically investigated, therefore, the primary aim of the present review is to introduce the role and function of CCN1/Cyr61 in the female reproductive system. The current review presents the molecular structure and biological function of CCN1/Cyr61 and provides detailed data on its expression pattern and contribution to the female reproductive system, including the role in embryogenesis and tumorigenesis.
\end{abstract}

Correspondence to: Professor Ying Chen or Professor Daozhen Chen, Wuxi Maternity and Child Health Care Hospital Affiliated to Nanjing Medical University, 48 Huaishu Lane, Chong'an, Wuxi, Jiangsu 214002, P.R. China

E-mail: yingchen8@163.com

E-mail: chendaozhen@163.com

Abbreviations: ECM, extracellular matrix; HSPGs, heparin sulfate proteoglycans; Cyr61/CCN1, cysteine-rich angiogenic inducer 61; VEGF, vascular endothelial growth factor; PDGF, platelet-derived growth factor; TGF, transforming growth factor; IGFBP, insulin-like growth factor binding protein; vWC, von Willebrand factor type $\mathrm{C}$ repeats; TSP-1, thrombospondin type 1 ; FAK, integrin/focal adhesion kinase; GCA, gastric cardia adenocarcinoma; MSC, marrow stromal cells; EMT, endometriosis; EC, endometrial cancer

Key words: cysteine rich angiogenic inducer 61, reproductive system, embryogenesis, tumorigenesis

\section{Contents}

1. Introduction

2. CCN1/Cyr61 molecular structure

3. CCN1/Cyr61 biological functions

4. CCN1/Cyr61 and the female reproductive system

5. Conclusions

\section{Introduction}

Cysteine-rich angiogenic inducer 61 (CCN1/Cyr61) was originally revealed to act as a growth factor-inducible immediate-early gene, present in serum and platelet-derived growth factor-stimulated mouse BALB/c 3 T3 cells (1). As a member of CCN family, it was first cloned by O'Brien in 1990 via differential hybridization screening of a cDNA library from BALB/c 3 T3 clone A31 cells (2). The CCN family is composed of six members including CCN1/Cyr61, connective tissue growth factor, nephroblastoma overexpressed, Wnt-1-induced secreted protein (WISP)-1, WISP-2 and WISP-3 (3). CCN1/Cyr61 is a basic secreted protein localized on the cell surface, cell interior and the extracellular matrix (ECM). CCN1/Cyr61 targets cells including fibroblasts, epithelial cells, endothelial cells, smooth muscle cells and neurons through integrins and heparin sulfate proteoglycan (HSPG) receptors. CCN1/Cyr61 exhibits a variety of functions in differing target cells. The biological properties of CCN1/Cyr61 in the regulation of cell survival, proliferation, differentiation, migration, adhesion and synthesis of ECM have been demonstrated to be important in the progression of embryogenesis and tumorigenesis in the female reproductive system.

\section{CCN1/Cyr61 molecular structure}

Complementary DNA encoding the human CCN1/Cyr61 protein was isolated by Jay et al (4) from human embryonic tissues in 1997. It is located on human chromosome 1p22.3 and contains 5 exons, interspaced with 4 introns. As presented in Fig. 1, the first exon encodes the mRNA that is translated into secretory signal peptide protein. The following 4 exons (E2-E5) encode a mosaic Cyr61 domain. The transcription of Cyr61 may be promptly induced by a wide range of environmental stimulatory factors, including vascular 
endothelial growth factor (VEGF), fibroblast growth factor, platelet-derived growth factor (PDGF), transforming growth factor (TGF)- $\beta$, sphingosine 1-phosphate, angiotensin II and lipopolysaccharides, in addition to physical and environmental inputs including shear stress, mechanical stretch and oxygen deprivation (5-7). The open reading frame of CCN1/Cyr61 encodes a protein of 381 amino acid including 38 conserved cysteines.

Sequence analysis revealed the presence of a mosaic structure to the CCN1/Cyr61 protein, including four highly conserved modules (3). As presented in Fig. 1, from the $\mathrm{N}$ - to the C-terminal, the four structurally distinct modules of CCN1/Cyr61 are insulin-like growth factor binding protein (IGFBP)-like domain, von Willebrand factor type $\mathrm{C}$ repeats (vWC) domain, thrombospondin type 1 (TSP-1) repeat homology domain, and the $\mathrm{C}$-terminal domain that contains a cysteine-knot (8). Currently, the four structurally distinct modules of $\mathrm{CCN} 1 / \mathrm{Cyr} 61$ have been important targets to explore the biological function of the protein. Module I is the binding domain of IGFBP which consists of 68 amino acids and shares homology with the cysteine-rich N-terminal region of traditional IGFBPs. A previous study suggested that $\mathrm{CCN} 1 / \mathrm{Cyr} 61$ demonstrates a low affinity to IGFs (9). Module II consists of 68 amino acids and includes a vWC domain which exists in vWC factor, mucoprotein, thrombospondin and collagenous fiber. Module II may additionally have a role in oligomerization (3). Module III contains a motif firstly identified in TSP-1 repeat homology and subsequently observed in various extracellular proteins. TSP-1 homology is involved in binding to soluble and matrix sulfated glycoconjugates (10). A previous study revealed that Module III contains cell attachment sites (11). Module IV, the C-terminal domain, is present in PDGF, nerve growth factor and TGF- $\beta$. It has been hypothesized that Module IV may be involved with cell surface receptors (12). The modular structural organization of the $\mathrm{CCN} 1 / \mathrm{Cyr} 61$ protein suggests that its diverse biological functions may result from the combined actions of individual modules, either acting independently or in conjugation. The interaction of the module and different factors endows CCN1/Cyr61 with complex biological effects in the organism tissues, cell environment and at all developmental stages.

\section{CCN1/Cyr61 biological functions}

CCN1/Cyr61 coordinates the essential activities of life and demonstrates a diverse functional pattern in various pathological and physiological conditions, in addition to its role in various tissues and cells. CCN1/Cyr61 primarily binds to integrins and HSPGs in a cell-type specific manner, and thus mediates various biological activities via these interactions.

CCN1/Cyr61 mediates cellular processes. CCN1/Cyr61 has been reported to mediate numerous cellular activities, including cell adhesion, migration, proliferation and apoptosis. $\mathrm{CCN1/Cyr61} \mathrm{is} \mathrm{a} \mathrm{cell} \mathrm{adhesion} \mathrm{protein,} \mathrm{which} \mathrm{is} \mathrm{associated}$ with the adhesion activities of endothelial cells, fibroblasts cells, smooth muscle cells, monocytes and platelets, through binding to particular integrins (Table I) (13-18). Integrin $\alpha_{v} \beta_{3}$, $\alpha_{\mathrm{v}} \beta_{5}, \alpha_{\mathrm{II}} \beta_{3}, \alpha_{6} \beta_{1}$, and $\alpha_{\mathrm{M}} \beta_{2}$ serve as adhesion receptors for
CCN1/Cyr61 on different cell types which are summarized in Table I. It has previously been demonstrated that cell adhesive properties of CCN1/Cyr61 in human umbilical vein endothelial cells are mediated through interaction with integrin $\alpha_{v} \beta_{3}(14)$. In addition, it was demonstrated that $\mathrm{CCN} 1 / \mathrm{Cyr} 61$ mediates endothelial cell adhesion through interaction with $\alpha_{6} \beta_{1}(13)$. $\mathrm{CCN} 1 / \mathrm{Cyr} 61$ promotes cell adhesion indirectly by altering the structure of the ECM protein. Kireeva et al (19) reported that CCN1/Cyr61 mediates cell and ECM and cell-cell adhesion by connecting with ECM and the cell membrane.

Cell migration is a complex biological process which involves a series of stimulating factors, signaling pathways and molecular mechanisms. It has been demonstrated that $\mathrm{CCN} 1 / \mathrm{Cyr} 61$ regulates cell migration of fibroblasts and endothelial cells. Zhang et al (20) firstly verified that PDGF-induced CCN1/Cyr61 exhibits a key role in regulating smooth muscle cell migration by connecting intracellular PDGF-extracellular signal-regulated kinase and jun $\mathrm{N}$-terminal kinase signals with integrin/focal adhesion kinase (FAK) signaling. Fibroblasts may suppress the inflammatory response, and may be considered as a novel target for the therapy of inflammation. Huang et al (21) demonstrated that CCN1/Cyr61 markedly facilitates rheumatoid arthritis (RA) fibroblast-like synoviocyte invasion and migration and may act as a promising therapeutic target for RA treatment. Wei et al (22) suggested that $\mathrm{CCN} 1 / \mathrm{Cyr} 61$ expression is significantly associated with the metastasis of gastric cardia adenocarcinoma (GCA). It has therefore been hypothesized that $\mathrm{CCN} 1 / \mathrm{Cyr} 61$ may act as a metastatic biomarker for evaluating the prognosis of GCA and a potential molecular target for anti-metastatic therapy of GCA.

In addition to promoting cell adhesion and migration, CCN1/Cyr61 regulates cell survival and apoptosis. The overexpression of CCN1/Cyr61 activates the nuclear factor $(\mathrm{NF})-\mathrm{\kappa B}$ pathway and induces hepatic stellate cell apoptosis through endoplasmic reticulum stress and initiation of the unfolded protein response (23). Conversely, CCN1/Cyr61 expression promotes kidney tubular epithelial cell proliferation and cell apoptosis is inhibited (21). The functions of $\mathrm{CCN} 1 / \mathrm{Cyr} 61$ in promoting cell survival or inducing apoptosis in different cell-types is important to elucidate its role in tissue reconstruction.

CCN1/Cyr61 and angiogenesis. Previous studies have suggested $\mathrm{CCN} 1 / \mathrm{Cyr} 61$ is a primary physiological mediator of angiogenesis. CCN1/Cyr61 modulates vascular formation in vitro directly through binding to $\alpha_{v} \beta_{3}$ to enhance the endothelial cell adhesion, migration, proliferation and microtubule formation, or indirectly by accommodating the activity of VEGF/VEGF receptor. You et al (24) suggested that $\mathrm{CCN} 1 / \mathrm{Cyr} 61$ induces the expression of monocyte chemoattractant protein-1 to mediate angiogenesis via the $\alpha_{v} \beta_{3}$ integrin, FAK, phosphoinositide-3-kinase/Akt Serine/Threonine Kinase 1 (Akt) and the IKB kinase signaling pathways in monkey chorioretinal vessel endothelial cells RF/6A (24). A previous study investigating pancreatic neuroendocrine tumors revealed a positive correlation between CCN1/Cyr61 expression levels and tumor angiogenesis, which suggests an ancillary function of CCN1/Cyr61 in vascular development (25). CCN1/Cyr61 was revealed to be expressed in the placenta, cardiovascular, 
skeletal and nervous systems during embryonic development. CCN1/Cyr61 expression levels are additionally significantly decreased in pre-eclamptic placentas (26). This suggests that CCN1/Cyr61 is involved in placental angiogenesis and may be important in the pathogenesis of pre-eclampsia. CCN1/Cyr61-deficient mice lead to a placental vasculogenesis deficiency with incomplete vascular nets. A previous study reported $\sim 30 \%$ of mice died from the chorioallantoic junction defect in the early stage of pregnancy and the others died in the middle of pregnancy due to placental vascular insufficiency and extensive loss in the vasculature integrity (27). Overall, these results demonstrate that $\mathrm{CCN} 1 / \mathrm{Cyr} 61$ is critically involved in developmental angiogenesis.

CCN1/Cyr61 and chondrogenesis. CCN1/Cyr61 is important in cartilage cell differentiation and chondrogenesis. The expression of $\mathrm{CCNl} / \mathrm{Cyr} 61$ is closely associated with angiogenesis and the process of the differentiation from marrow stromal cells (MSC) to chondrocytes during embryogenesis (28). In adult cartilage, Chijiiwa et al (29) demonstrated that CCN1/Cyr61 is involved in chondrocyte cloning in osteoarthritic cartilage by inhibiting the activity of ADAM metallopeptidase with thrombospondin type 1 motif 4 (ADAMTS; aggrecanase-1). Conversely, the emergence of $\mathrm{CCN} 1 / \mathrm{Cyr} 61$ may lead to the replacement of bone tissue by cartilage through inducing angiogenesis. A previous study revealed that $\mathrm{CCN1/Cyr61} \mathrm{may} \mathrm{be}$ associated with the induction of a passage-dependent decrease in chondrogenic differentiation and a passage-dependent increase in osteogenic potential of tonsil-derived MSC (30).

\section{CCN1/Cyr61 and the female reproductive system}

CCN1/Cyr61 and reproduction. Mammalian reproduction is a complex process involving ovulation, fertilization, embryo development and implantation and the failure of any process may result in sterility, malformations or adverse pregnancy outcomes. Previous studies demonstrated that CCN1/Cyr61 is expressed on the corpus luteum (CL) (31), conceptus and endometrium in early pregnancy (32), trophoblastic origin of the placenta (33), midterm fetal smooth muscle vessel walls of the arterial circulatory system (34), endothelial cells of vessels surrounding the cloaca, embryonic hippocampal neurons (35) and mesodermal and ectodermal mesenchymal cells (28). It contributes to the process of embryogenesis including the implantation (36), fetal neovascularization (34), fetal brain development (35), fetal cartilaginous development (28) and fetal-maternal cross-talk (32). The abnormal expression of $\mathrm{CCN1/Cyr61} \mathrm{may} \mathrm{result} \mathrm{in} \mathrm{pre-eclampsia,} \mathrm{epispadias,} \mathrm{embry-}$ onic death resulting from disability of allantoic fusion and the disturbance of vascular dysplasia $(34,37)$.

$\mathrm{CL}$, which is a glandular-like structure rich in blood vessels and exhibits a key role in mammalian reproduction. The development of the follicle into the CL involves neovascularization, and previous studies have demonstrated that $\mathrm{CCN1} / \mathrm{Cyr} 61$ may mediate this process (Fig. 2). Zhang et al (31) suggested that $\mathrm{CCNl} / \mathrm{Cyr} 61$ is expressed in the CL of cows and the expression is upregulated at days 4, 6, 10 and 16 of CL. It was therefore hypothesized that the upregulation may be associated with the angiogenesis of the CL. A further study conducted by Romereim et al (38) demonstrated that the CCNl/Cyr61 gene is highly expressed in small luteal cells isolated from cows. These findings support the hypothesis that CCN1/Cyr61 is important in the development of the CL. However, the expression pattern, regulation and function of $\mathrm{CCNl} / \mathrm{Cyr} 61$ in human CLs still remains unclear and requires further investigation.

Implantation is an important process during the early development of embryos. $\mathrm{CCN} / \mathrm{Cyr} 61$ has previously been suggested to act as a mediator for embryo implantation. It has previously been detected to be upregulated in the invasive extravillous trophoblasts and unclosed endometrial luminal epithelium surrounding the embryo (39). Pre-eclampsia is one of the common complications of pregnancy, which originates in the placenta and results in complication of maternal and fetal health (40). The hypothesis of the etiology has been recognized as insufficient invasion of trophoblast cells into the decidua and the obstruction of maternal spiral artery remodeling (41). This leads to an inadequate blood flow in the placenta and may result in the inhibition of placental development and intrauterine growth restrictions (42). Recombinant $\mathrm{CCN1/Cyr61} \mathrm{protein-stimulated} \mathrm{trophoblast} \mathrm{cells} \mathrm{demonstrate}$ a stronger invasion ability compared with cells without the stimulus (43). Chen et al (33) revealed that CCN1/Cyr61 mRNA expression levels in placentas of pre-eclampsia cases are decreased compared with than those in normal pregnancies. Furthermore, Kipkeew et al (36) indicated that $\mathrm{CCN} / \mathrm{Cyr} 61$ and $\mathrm{CCN} 3$ promote the migration capability of trophoblast cells by activating FAK and Akt kinase. This evidence verified the hypothesis of a negative correlation between the expression of $\mathrm{CCNl} / \mathrm{Cyr} 61$ and pre-eclampsia. These findings may act as a research foundation for the early diagnosis and prediction of pre-eclampsia through screening for expression of $\mathrm{CCN1} / \mathrm{Cyr} 61$. Zhang et al (44) suggested that that micro (mi)RNA 155 contributes to pre-eclampsia development by downregulating $\mathrm{CCNl} / \mathrm{Cyr} 61$. MiRNAs are relatively stable and the identification of circulating miRNAs involved in promoting the development of pre-eclampsia by regulating the expression of CCNl/Cyr61 in the plasma of pregnant woman, may aid in the clinical prediction of pre-eclampsia.

$\mathrm{CCNl} / \mathrm{Cyr} 61$ is additionally important in the maintenance of the pregnancy and the embryonic development. Klein et al (32) demonstrated that CCN1/Cyr61 is co-expressed on the conceptus and endometrium in the early stage of pregnancy and involved the maintenance of the early pregnancy. It contributes to the cross-talk of the conceptus and endometrium through affecting the proliferation and differentiation of endometrial and trophectoderm cells and stimulation of endometrial-angiogenesis. Furthermore, previous studies have demonstrated that $\mathrm{CCN} 1 / \mathrm{Cyr} 61$ regulates neovascularization and matrix remodeling in the process of embryogenesis. CCNl/Cyr61 gene knock-out mice often suffer from vascular anomalies of placenta and embryonic fatalities (34). The expression of CCN1/Cyr61 may be detected in endothelial cells of vessels surrounding the cloaca and the umbilical cord on gestational days 10 and 11.5 in mice, which suggests it may be involved in the development of human epispadias (37). In addition, the expression of CCN1/Cyr61 in fetal hippocampal neurons has been demonstrated to be increased compared with mature hippocampal neurons, which suggests it may exhibit an important role during development of the embryonic brain (35). Overall, 
Table I. Adhesion receptor for CCN1/Cyr61 on different cell types.

\begin{tabular}{llcc}
\hline Author, year & \multicolumn{1}{c}{ Cell types } & Integrins & (Refs.) \\
\hline Heng, 2006 & Endothelial cells & $\alpha_{\mathrm{v}} \beta_{3}, \alpha_{6} \beta_{1}$ & $(13,14)$ \\
Kireeva, 1998 & Fibroblasts cell & $\alpha_{6} \beta_{1}$ & $(15)$ \\
Grzeszkiewicz, 2002 & Smooth muscle cells & $\alpha_{6} \beta_{1}$ & $(16)$ \\
Schober, 2002 & Monocytes & $\alpha_{\mathrm{M}} \beta_{2}$ & $(17)$ \\
Jedsadayanmata, 1999 & Platelets & $\alpha_{\mathrm{IIb}} \beta_{3}$ & $(18)$ \\
\hline
\end{tabular}

Cyr61/CCN1, cysteine-rich angiogenic inducer 61.
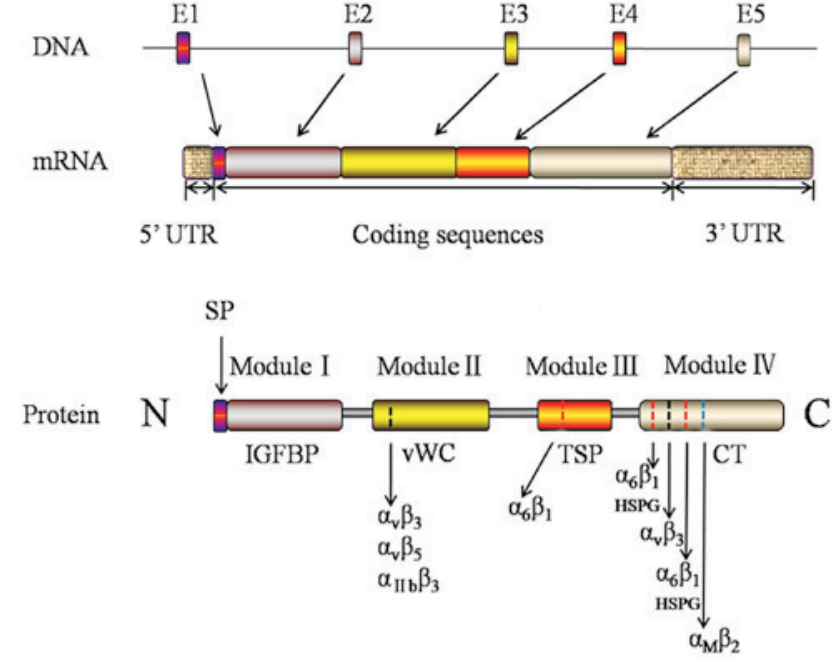

Figure 1. Gene and modular domain structure of CCN1/Cyr61. The CCN1/Cyr61 gene is transcribed into RNA and then translated into the protein. Each exon and its corresponding RNA and protein is depicted as a rectangle with a unique color. The module name of the protein is presented under the rectangle. The binding sites of integrin and HSPGs in the $\mathrm{CCN} 1 / \mathrm{Cyr} 61$ protein are marked as dotted lines. CCN1/Cyr61, cysteine-rich angiogenic inducer 61; UTR, untranslated region; IGFBP, insulin-like growth factor binding protein; vWC, von Willebrand factor type C repeats; TSP-1, thrombospondin type $1 ;$ HSPG, heparan sulfate proteoglycans.

$\mathrm{CCN1} / \mathrm{Cyr} 61$ is important role in the female reproductive system.

CCN1/Cyr61 and female reproductive tumors. It was previously demonstrated that $\mathrm{CCNl} / \mathrm{Cyr} 61$ acts as a tumor-suppressor or promoter in different types of tumors depending on the complex external environment (45-47). $\mathrm{CCNl} / \mathrm{Cyr} 61$ is involved in the occurrence and development of tumors through its role in tumor angiogenesis, tumor cell proliferation and apoptosis and tumor metastasis $(25,47-49)$. An overview of the expression and function of $\mathrm{CCNl} / \mathrm{Cyr} 61$ in female reproductive tumors is presented in Table II (50-61). Further research and understanding of the function of $\mathrm{CCN} / \mathrm{Cyr} 61$ in different types of cancer may provide a promising basis for cancer prognosis and therapy.

Uterine leiomyoma (UL) is the most common benign tumor of the female reproductive system, which is hormone dependent and results from smooth muscle cell proliferation (62). Molecular genetic studies have provided compelling evidence that abnormally expressed genes have an important influence on UL occurrence $(63,64)$. CCNl/Cyr61 expression in UL is downregulated when compared with matched normal uterine smooth muscle cells, suggesting it may exhibit a tumor-suppressor role (50). Di Tommaso et al (51) revealed that estrogen upregulates the expression of the $\mathrm{CCNl} / \mathrm{Cyr} 61$ gene in myometrium tissue, however has no influence on the expression of the $\mathrm{CCNl} / \mathrm{Cyr} 61$ gene in fibroid tissue, detected via gene expression analysis. The results indicated that the expression of $\mathrm{CCNl} / \mathrm{Cyr} 61$ may not be regulated by the estrogen receptor in uterine fibroids. Fundamental research was conducted by Wallace et al (52) to determine if hypoxia induced CCN1/Cyr61 secretion through the Endothelin- $\mathrm{A}\left(\mathrm{ET}_{\mathrm{A}}\right)$ receptor in UL. However, the results identified that blockade of the ETA receptor demonstrated no significant influence on the increase of $\mathrm{CCNl} / \mathrm{Cyr} 61$ expression under normoxic or hypoxic conditions and the secretion of $\mathrm{CCNl} / \mathrm{Cyr} 61$ may not be regulated by the ETA receptor in UL. The exact mechanism still remains unclear and further investigation is required in the future.

Endometriosis (EMT) is one of the most common diseases of obstetrics and gynecology, and commonly associates with infertility in women of child-bearing age (65-67). The specific pathogenesis of EMT remains to be fully elucidated. Although EMT is a frequently occurring benign disease, it is characterized by malignant behaviors including recurrence and metastasis $(68,69)$. At present, various pharmacotherapies and other methods have been proposed to treat EMT $(70,71)$. However, their usage has been limited due to strong and obvious adverse effects $(65,72)$. It was previously demonstrated that the expression of the $\mathrm{CCNl} / \mathrm{Cyr} 61$ gene is controlled by estrogen and is enhanced in endometria of women suffering from EMT and in endometriotic lesions, suggesting that $\mathrm{CCNl} / \mathrm{Cyr} 61$ may act as a useful maker gene for EMT (53). A further study identified that estrogen promotes the expression of the CCNl/Cyr61 gene during the early stages of EMT-like establishment and the $\mathrm{CCN1} / \mathrm{Cyr} 61$ gene contributes to regulation of cell proliferation and the generation of vasculature in the development of lesions, using the conditional knockout mice lacking uterine CCN1/Cyr61 (54). Furthermore, Gashaw et al (73) demonstrated that the expression level of $\mathrm{CCN1} / \mathrm{Cyr} 61$ is upregulated by hypoxia-inducible factor $1-\alpha$, through use of the benign endometrial cell line. The study suggests that targeting $\mathrm{CCNl} / \mathrm{Cyr} 61$ signaling during the early stages of lesion establishment may provide a novel treatment method for EMT. 
Table II. Expression and function of $\mathrm{CCNl} / \mathrm{Cyr} 61$ in female reproductive tumors.

\begin{tabular}{|c|c|c|c|c|}
\hline $\begin{array}{l}\text { Author, } \\
\text { Year }\end{array}$ & $\begin{array}{l}\text { Female } \\
\text { reproductive tumors }\end{array}$ & $\begin{array}{l}\text { Expression } \\
\text { level }\end{array}$ & Function & (Refs.) \\
\hline $\begin{array}{l}\text { Arslan, 2005; } \\
\text { Di Tommaso, 2013; } \\
\text { Wallace, } 2014\end{array}$ & UL & Downregulated & Suppressor of UL & $(50-52)$ \\
\hline $\begin{array}{l}\text { Zhao, 2014; } \\
\text { Klein, } 2012\end{array}$ & EMT & $\begin{array}{l}\text { Upregulated by } \\
\text { estrogen or HIF- } \alpha\end{array}$ & $\begin{array}{l}\text { Promoter of EMT cell } \\
\text { proliferation, generation } \\
\text { of vasculature }\end{array}$ & $(53,54)$ \\
\hline $\begin{array}{l}\text { Chien, 2004; } \\
\text { Fournier, } 2014\end{array}$ & $\mathrm{EC}$ & $\begin{array}{l}\text { Downregulated in endometrial } \\
\text { tumors; Up-regulated in PCOS }\end{array}$ & $\begin{array}{l}\text { Suppress growth of endometrial } \\
\text { cancer cells, expression is } \\
\text { correlated with patient survival }\end{array}$ & $(55,56)$ \\
\hline $\begin{array}{l}\text { Joy, 2014; } \\
\text { Xie, } 2012\end{array}$ & Cervical cancer & Downregulated & Target therapy, clinical diagnosis & $(57,58)$ \\
\hline $\begin{array}{l}\text { Bartel, 2012; } \\
\text { Lee, 2012; } \\
\text { Lin, } 2014\end{array}$ & Ovarian cancer & Upregulated & $\begin{array}{l}\text { Promotes ovarian cancer } \\
\text { cell proliferation and inhibits } \\
\text { apoptosis, associated with } \\
\text { lymph node metastases }\end{array}$ & $(59-61)$ \\
\hline
\end{tabular}

Cyr61/CCN1, cysteine-rich angiogenic inducer 61; UL, uterine leiomyoma; EMT, endometriosis; EC, endometrial cancer; PCOS, polycystic ovarian syndrome; HIF- $\alpha$, hypoxia-inducible factor- $\alpha$.

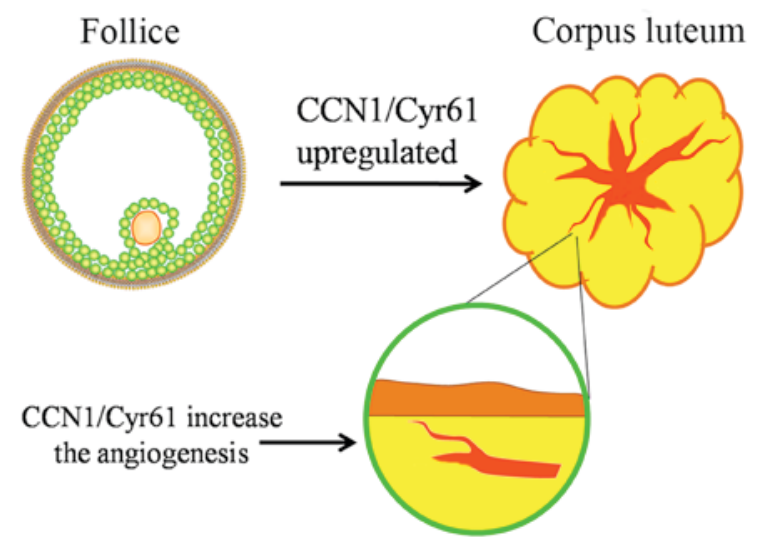

Figure 2. Expression and function of CCN1/Cyr61 in the CLs. The expression of $\mathrm{CCN} 1 / \mathrm{Cyr} 61$ is upregulated in $\mathrm{CL}$ and promotes angiogenesis. CCN1/Cyr61, cysteine-rich angiogenic inducer 61; CL, corpus luteum.

Endometrial cancer (EC) is a common malignant gynecological tumor, however non-invasive diagnostic tools for early and accurate diagnosis are still limited (74). Hormonal dysregulation is believed to contribute to the etiology of EC (75). Previous studies demonstrated that long-term replacement estrogen therapy is associated with a type I EC and progestational hormone is not sufficient to prevent this (56). Estrogen may upregulate the expression of $\mathrm{CCNl} / \mathrm{Cyr} 61$ and current data indicate that there is a significant increase of $\mathrm{CCNl} / \mathrm{Cyr} 61$ expression in the endometrium of women with polycystic ovarian syndrome and premalignant lesions. Hence, measures to detect the expression of $\mathrm{CCNl} / \mathrm{Cyr} 61$ may result in its use as an early diagnostic marker of type I EC cancer However, Chien et al (55) demonstrated that the expression level of Cyr61 is decreased in endometrial tumors compared with normal endometrium. At present, little is known regarding the antithetical function of $\mathrm{CCN} 1 / \mathrm{Cyr} 61$ in EC. Previous findings from Witek et al (76) revealed that $\mathrm{CCN1} / \mathrm{Cyr} 61$ genes expressed in all cancer grades and their expressions levels are potentially correlated with the survival of patients. Therefore, detecting the expression level of $\mathrm{CCN1} / \mathrm{Cyr} 61$ may act as a novel non-invasive diagnostic tool for early and accurate diagnosis of EC.

Cervical cancer is one of the most common gynecological tumors occurring in women worldwide, with >190,000 newly diagnosed cases per year (77). The human papillomavirus infection is an important factor in the development of cervical cancer, and vaccination against it provides an effective way to prevent development of cervical cancer. However, the pathogenesis underlying cervical cancer remains unknown, and its incidence is increasing each year. Xie et al (58) demonstrated that $\mathrm{CCNl} / \mathrm{Cyr} 61$ gene expression is downregulated in cervical cancer compared with normal tissues and its expression level is inversely correlated with miR-205 expression. miR-205 has been reported to contribute to the development of cervical cancer and regulate cell proliferation and migration in human cervical cancer cells. The identified inverse expression pattern between $\mathrm{CCN} 1 / \mathrm{Cyr} 61$ and miR-205 suggests that CCN1/Cyr61 may be one of the target genes of miR-205. In addition, by performing genome-wide expression analysis of miRNAs, in addition to investigation of mRNAs in cervical cancer, Joy et al (57) demonstrated that CCN1/Cyr61 is a key gene involved in vascularization of tumors and suggests its expression level is negatively associated with the level of hsa-miR-221. The roles of CCN1/Cyr61 in human cervical cancer may provide novel insights into carcinogenesis and the clinical diagnosis.

Ovarian cancer is the leading cause of gynecological malignancy-associated mortalities worldwide and the 
symptoms are insidious in onset $(78,79)$. The search for novel biomarkers for early diagnosis in ovarian carcinoma may provide effective medical support. Lee et al (60) demonstrated that $\mathrm{CCN} 1 / \mathrm{Cyr} 61$ promotes ovarian cancer cell proliferation and inhibits apoptosis by regulating p53 and $\mathrm{NF}-\kappa \mathrm{B}$ expression through the phosphoinositide-3-kinase/AKT Serine/Threonine kinase/mechanistic target of rapamycin signaling pathways. Bartel et al (59) revealed that CCN1/Cyr61 is preferentially expressed in high grade serous carcinomas. It was demonstrated that $\mathrm{CCN1} / \mathrm{Cyr} 61$ expression is significantly upregulated in ovarian epithelial carcinoma tissue compared with benign ovarian tumor tissue samples and the levels of $\mathrm{CCNl} / \mathrm{Cyr} 61$ are associated with lymph node metastases (61). $\mathrm{CCNl} / \mathrm{Cyr} 61$ may therefore be useful in targeted diagnosis and therapy in ovarian epithelial carcinoma.

\section{Conclusions}

The present review systematically clarified the biological functions of CCN1/Cyr61 and its associated roles in the female reproductive system, including embryogenesis and tumorigenesis. $\mathrm{CCN1/Cyr61} \mathrm{may} \mathrm{regulate} \mathrm{numerous} \mathrm{cellular}$ activities, angiogenesis and chondrogenesis. It is important in the reproduction and the occurrence and development of tumors in the reproductive system. However, the underlying mechanism that results in $\mathrm{CCNl} / \mathrm{Cyr} 61$ acting as a tumor-suppressor or tumor-promoter in different types reproductive system tumors, remains to be fully elucidated, due to the complicated external environment, including complex crosstalk of intracellular molecules and multi-module activated signal transduction pathways.

\section{Acknowledgements}

The present review was supported by the National Natural Science Foundation of China (grant nos. 81671473 and 81602728), the Youth Talent's Project of Jiangsu Province (grant no. QNRC2016164) and Provincial Foundation of Jiangsu Province (grant nos. BK20131151 and BE2016633).

\section{References}

1. Lau LF and Nathans D: Identification of a set of genes expressed during the G0/G1 transition of cultured mouse cells. EMBO J 4: 3145-3151, 1985.

2. O'Brien TP, Yang GP, Sanders L and Lau LF: Expression of cyr61, a growth factor-inducible immediate-early gene. Mol Cell Biol 10: 3569-3577, 1990.

3. Bork P: The modular architecture of a new family of growth regulators related to connective tissue growth factor. FEBS Lett 327: 125-130, 1993.

4. Jay P, Bergé-Lefranc JL, Marsollier C, Méjean C, Taviaux S and Berta P: The human growth factor-inducible immediate early gene, CYR61, maps to chromosome 1p. Oncogene 14: 1753-1757, 1997.

5. Borkham-Kamphorst E, Schaffrath C, Van de Leur E, Haas U, Tihaa L, Meurer SK, Nevzorova YA, Liedtke C and Weiskirchen R: The anti-fibrotic effects of CCN1/CYR61 in primary portal myofibroblasts are mediated through induction of reactive oxygen species resulting in cellular senescence, apoptosis and attenuated TGF- $\beta$ signaling. Biochim Biophys Acta 1843: 902-914, 2014.

6. Chen Y and Du XY: Functional properties and intracellular signaling of CCN1/Cyr61. J Cell Biochem 100: 1337-1345, 2007.

7. Chin LH, Hsu SP, Zhong WB and Liang YC: Involvement of cysteine-rich protein 61 in the epidermal growth factor-induced migration of human anaplastic thyroid cancer cells. Mol Carcinog 55: 622-632, 2016.
8. Rachfal AW and Brigstock DR: Structural and functional properties of CCN proteins. Vitam Horm 70: 69-103, 2005.

9. Berschneider B and Königshoff M: WNT1 inducible signaling pathway protein 1 (WISP1): A novel mediator linking development and disease. Int J Biochem Cell Biol 43: 306-309, 2011.

10. Choi J, Lin A, Shrier E, Lau LF, Grant MB and Chaqour B: Degradome products of the matricellular protein CCN1 as modulators of pathological angiogenesis in the retina. J Biol Chem 288: 23075-23089, 2013.

11. Lin J, Huo R, Wang L, Zhou Z, Sun Y, Shen B, Wang R and Li N: A novel anti-Cyr61 antibody inhibits breast cancer growth and metastasis in vivo. Cancer Immunol Immunother 61: 677-687, 2012.

12. Qin Z, Fisher GJ and Quan T: Cysteine-rich protein 61 (CCN1) domain-specific stimulation of matrix metalloproteinase-1 expression through aVb3 integrin in human skin fibroblasts. J Biol Chem 288: 12386-12394, 2013.

13. Heng EC, Huang Y, Black SA Jr and Trackman PC: CCN2, connective tissue growth factor, stimulates collagen deposition by gingival fibroblasts via module 3 and alpha6- and beta1 integrins. J Cell Biochem 98: 409-420, 2006.

14. Kireeva ML, Lam SC and Lau LF: Adhesion of human umbilical vein endothelial cells to the immediate-early gene product Cyr61 is mediated through integrin alphavbeta3. J Biol Chem 273: 3090-3096, 1998.

15. Chen N, Chen CC and Lau LF: Adhesion of human skin fibroblasts to Cyr61 is mediated through integrin alpha 6beta 1 and cell surface heparan sulfate proteoglycans. J Biol Chem 275: 24953-24961, 2000.

16. Grzeszkiewicz TM, Lindner V, Chen N, Lam SC and Lau LF: The angiogenic factor cysteine-rich 61 (CYR61, CCN1) supports vascular smooth muscle cell adhesion and stimulates chemotaxis through integrin alpha(6)beta(1) and cell surface heparan sulfate proteoglycans. Endocrinology 143: 1441-1450, 2002.

17. Schober JM, Chen N, Grzeszkiewicz TM, Jovanovic I, Emeson EE, Ugarova TP, Ye RD, Lau LF and Lam SC: Identification of integrin alpha(M)beta(2) as an adhesion receptor on peripheral blood monocytes for Cyr61 (CCN1) and connective tissue growth factor (CCN2): Immediate-early gene products expressed in atherosclerotic lesions. Blood 99: 4457-4465, 2002.

18. Jedsadayanmata A, Chen CC, Kireeva ML, Lau LF and Lam SC: Activation-dependent adhesion of human platelets to Cyr61 and Fisp12/mouse connective tissue growth factor is mediated through integrin alpha(IIb)beta(3). J Biol Chem 274: 24321-24327, 1999.

19. Kireeva ML, Mo FE, Yang GP and Lau LF: Cyr61, a product of a growth factor-inducible immediate-early gene, promotes cell proliferation, migration, and adhesion. Mol Cell Biol 16: 1326-1334, 1996.

20. Zhang F, Hao F, An D, Zeng L, Wang Y, Xu X and Cui MZ: The matricellular protein Cyr61 is a key mediator of platelet-derived growth factor-induced cell migration. J Biol Chem 290: 8232-8242, 2015.

21. Huang TL, Mu N, Gu JT, Shu Z, Zhang K, Zhao JK, Zhang C, Hao Q, Li WN, Zhang WQ, et al: DDR2-CYR61-MMP1 signaling pathway promotes bone erosion in rheumatoid arthritis through regulating migration and invasion of fibroblast-like synoviocytes. J Bone Miner Res 32: 407-418, 2017.

22. Wei J, Yu G, Shao G, Sun A, Chen M, Yang W and Lin Q: CYR61 (CCN1) is a metastatic biomarker of gastric cardia adenocarcinoma. Oncotarget 7: 31067-31078, 2016.

23. Borkham-Kamphorst E, Steffen BT, Van de Leur E, Haas U, Tihaa L, Friedman SL and Weiskirchen R: CCN1/CYR61 overexpression in hepatic stellate cells induces ER stress-related apoptosis. Cell Signal 28: 34-42, 2016.

24. You JJ, Yang CH, Yang CM and Chen MS: Cyr61 induces the expression of monocyte chemoattractant protein-1 via the integrin avb3, FAK, PI3K/Akt, and NF-kB pathways in retinal vascular endothelial cells. Cell Signal 26: 133-140, 2014.

25. Huang YT, Lan Q, Ponsonnet L, Blanquet M, Christofori G, Zaric J and Rüegg C: The matricellular protein CYR61 interferes with normal pancreatic islets architecture and promotes pancreatic neuroendocrine tumor progression. Oncotarget 7: 1663-1674, 2016.

26. Li X, Li C, Dong X and Gou W: MicroRNA-155 inhibits migration of trophoblast cells and contributes to the pathogenesis of severe preeclampsia by regulating endothelial nitric oxide synthase. Mol Med Rep 10: 550-554, 2014.

27. Lau LF: CCN1 and CCN2: Blood brothers in angiogenic action. J Cell Commun Signal 6: 121-123, 2012. 
28. O'Brien TP and Lau LF: Expression of the growth factor-inducible immediate early gene cyr61 correlates with chondrogenesis during mouse embryonic development. Cell Growth Differ 3: 645-654, 1992.

29. Chijiiwa M, Mochizuki S, Kimura T, Abe H, Tanaka Y, Fujii Y, Shimizu H, Enomoto H, Toyama Y and Okada Y: CCN1 (Cyr61) is overexpressed in human osteoarthritic cartilage and inhibits ADAMTS-4 (Aggrecanase 1) activity. Arthritis Rheumatol 67: 1557-1567, 2015

30. Yu Y,Park YS, Kim HS, Kim HY,Jin YM,Jung SC, Ryu KH and Jo I: Characterization of long-term in vitro culture-related alterations of human tonsil-derived mesenchymal stem cells: Role for CCN1 in replicative senescence-associated increase in osteogenic differentiation. J Anat 225: 510-518, 2014

31. Zhang B, Tsang PC, Pate JL and Moses MA: A role for cysteine-rich 61 in the angiogenic switch during the estrous cycle in cows: Regulation by prostaglandin F2alpha. Biol Reprod 85: 261-268, 2011.

32. Klein C: Novel equine conceptus?endometrial interactions on Day 16 of pregnancy based on RNA sequencing. Reprod Fertil Dev: May 5, 2015 (Epub ahead of print).

33. Chen X, Liu Y, Xu X and Chen H: Correlation of Cyr61 and CTGF in placentas from the late pre-eclamptic pregnancy. J Perinat Med 40: 199-200, 2012.

34. Mo FE, Muntean AG, Chen CC, Stolz DB, Watkins SC and Lau LF: CYR61 (CCN1) is essential for placental development and vascular integrity. Mol Cell Biol 22: 8709-8720, 2002.

35. Malik AR, Urbanska M, Gozdz A, Swiech LJ, Nagalski A, Perycz M, Blazejczyk M and Jaworski J: Cyr61, a matricellular protein, is needed for dendritic arborization of hippocampal neurons. J Biol Chem 288: 8544-8559, 2013.

36. Kipkeew F, Kirsch M, Klein D, Wuelling M, Winterhager E and Gellhaus A: CCN1 (CYR61) and CCN3 (NOV) signaling drives human trophoblast cells into senescence and stimulates migration properties. Cell Adh Migr 10: 163-178, 2016.

37. Draaken M, Proske J, Schramm C, Wittler L, Bartels E, Nöthen MM, Reutter H and Ludwig M: Embryonic expression of the cysteine rich protein 61 (CYR61) gene: A candidate for the development of human epispadias. Birth Defects Res A Clin Mol Teratol 88: 546-550, 2010.

38. Romereim SM, Summers AF, Pohlmeier WE, Zhang P, Hou X, Talbott HA, Cushman RA, Wood JR, Davis JS and Cupp AS: Gene expression profiling of bovine ovarian follicular and luteal cells provides insight into cellular identities and functions. Mol Cell Endocrinol 439: 379-394, 2017.

39. Chen Y, Ni H, Ma XH, Hu SJ, Luan LM, Ren G, Zhao YC, Li SJ, Diao HL, Xu X, et al: Global analysis of differential lumina epithelial gene expression at mouse implantation sites. J Mol Endocrinol 37: 147-161, 2006.

40. Wu P, Kwok CS, Haththotuwa R, Kotronias RA, Babu A, Fryer AA, Myint PK, Chew-Graham CA and Mamas MA: Pre-eclampsia is associated with a twofold increase in diabetes: A systematic review and meta-analysis. Diabetologia 59: 2518-2526, 2016.

41. Hodgins S: Pre-eclampsia as underlying cause for perinatal deaths: Time for action. Glob Health Sci Pract 3: 525-527, 2015.

42. Chaiworapongsa T, Chaemsaithong P, Yeo L and Romero R: Pre-eclampsia part 1: Current understanding of its pathophysiology. Nat Rev Nephrol 10: 466-480, 2014

43. Zhang X, Yan G, Diao Z, Sun H and Hu Y: NUR77 inhibits the expression of TIMP2 and increases the migration and invasion of HTR-8/SVneo cells induced by CYR61. Placenta 33: 561-567, 2012.

44. Zhang Y, Diao Z, Su L, Sun H, Li R, Cui H and Hu Y: MicroRNA-155 contributes to preeclampsia by down-regulating CYR61. Am J Obstet Gynecol 202: 466.e1-e7, 2010.

45. Huang J, Gao K, Lin J and Wang Q: MicroRNA-100 inhibits osteosarcoma cell proliferation by targeting Cyr61. Tumour Biol 35: 1095-1100, 2014.

46. Sarkissyan S, Sarkissyan M, Wu Y, Cardenas J, Koeffler HP and Vadgama JV: IGF-1 regulates Cyr61 induced breast cancer cel proliferation and invasion. PLoS One 9: e103534, 2014.

47. Johnson SK, Stewart JP, Bam R, Qu P, Barlogie B, van Rhee F, Shaughnessy JD Jr, Epstein J and Yaccoby S: CYR61/CCN1 overexpression in the myeloma microenvironment is associated with superior survival and reduced bone disease. Blood 124: 2051-2060, 2014.

48. Shigeoka M, Urakawa N, Nishio M, Takase N, Utsunomiya S, Akiyama H, Kakeji Y, Komori T, Koma Y and Yokozaki H: Cyr61 promotes CD204 expression and the migration of macrophages via MEK/ERK pathway in esophageal squamous cell carcinoma. Cancer Med 4: 437-446, 2015.
49. Maity G, Mehta S, Haque I, Dhar K, Sarkar S, Banerjee SK and Banerjee S: Pancreatic tumor cell secreted CCN1/Cyr61 promotes endothelial cell migration and aberrant neovascularization. Sci Rep 4: 4995, 2014.

50. Arslan AA, Gold LI, Mittal K, Suen TC, Belitskaya-Levy I, Tang MS and Toniolo P: Gene expression studies provide clues to the pathogenesis of uterine leiomyoma: New evidence and a systematic review. Hum Reprod 20: 852-863, 2005.

51. Di Tommaso S, Massari S, Malvasi A, Bozzetti MP and Tinelli A Gene expression analysis reveals an angiogenic profile in uterine leiomyoma pseudocapsule. Mol Hum Reprod 19: 380-387, 2013.

52. Wallace K, Chatman K, Spencer SK, Johnson V and LaMarca B: 'Special research presentation' endothelin regulation of cyr61 in uterine leiomyomas. Fertil Steril 102 (Suppl): e106, 2014.

53. Zhao Y, Li Q, Katzenellenbogen BS, Lau LF, Taylor RN, Bagchi IC and Bagchi MK: Estrogen-induced CCN1 is critical for establishment of endometriosis-like lesions in mice. Mol Endocrinol 28: 1934-1947, 2014.

54. Klein R, Stiller S and Gashaw I: Epidermal growth factor upregulates endometrial CYR61 expression via activation of the JAK2/STAT3 pathway. Reprod Fertil Dev 24: 482-489, 2012.

55. Chien W, Kumagai T, Miller CW, Desmond JC, Frank JM, Said JW and Koeffler HP: Cyr61 suppresses growth of human endometrial cancer cells. J Biol Chem 279: 53087-53096, 2004.

56. Fournier A, Dossus L, Mesrine S, Vilier A, Boutron-Ruault MC, Clavel-Chapelon F and Chabbert-Buffet N: Risks of endometrial cancer associated with different hormone replacement therapies in the E3 N cohort, 1992-2008. Am J Epidemiol 180: 508-517, 2014.

57. Joy J: Epigenetic regulation of key genes involved in cervical malignancy. 44, 2014.

58. Xie H, Zhao Y, Caramuta S, Larsson C and Lui WO: miR-205 expression promotes cell proliferation and migration of human cervical cancer cells. PLoS One 7: e46990, 2012

59. Bartel F, Balschun K, Gradhand E, Strauss HG, Dittmer J and Hauptmann S: Inverse expression of cystein-rich 61 (Cyr61/CCN1) and connective tissue growth factor (CTGF/CCN2) in borderline tumors and carcinomas of the ovary. Int J Gynecol Pathol 31 : 405-415, 2012

60. Lee KB, Byun HJ, Park SH, Park CY, Lee SH and Rho SB: CYR61 controls p53 and NF-kB expression through PI3K/Akt/mTOR pathways in carboplatin-induced ovarian cancer cells. Cancer Lett 315: 86-95, 2012

61. Lin Y, Xu T, Tian G and Cui M: Cysteine-rich, angiogenic inducer, 61 expression in patients with ovarian epithelial carcinoma. J Int Med Res 42: 300-306, 2014.

62. Po LK and Liu GY: Development of uterine smooth muscle tumour of uncertain malignant potential (STUMP) after laparoscopic myomectomy of an atypical leiomyoma. J Minim Invasive Gynecol 22: S231, 2015.

63. Joseph NM, Solomon DA, Frizzell N, Rabban JT, Zaloudek C and Garg K: Morphology and immunohistochemistry for 2SC and $\mathrm{FH}$ aid in detection of fumarate hydratase gene aberrations in uterine leiomyomas from young patients. Am J Surg Pathol 39: 1529-1539, 2015.

64. Kubínová K, Mára M, Horák P and Kuzel D: Genetic factors in etiology of uterine fibroids. Ceska Gynekol 77: 58-60, 2012 (In Czech).

65. Abu Hashim H: Aromatase inhibitors for endometriosis-associated infertility; Do we have sufficient evidence? Int J Fertil Steril 10: 270-277, 2016.

66. Bhatti M, Arnold A, Ketheeswaran A, Nesbitt-Hawes E, Deans R and Abbott $\mathrm{J}$ : A comparison of examination and surgical findings in women with endometriosis. J Minim Invasive Gynecol 22: S55-S56, 2015

67. Modotte WP, Modotti CC, Dias DS, Bueloni-Dias FN and Rodrigues NP: Endometriosis and infertility setup during hysterossalpingogram. J Minim Invasive Gynecol 22: S178, 2015.

68. Cozzolino M, Nasioudis D, Sisti G and Coccia ME: Malignant transformation of vaginal endometriosis-a review of literature. Gynecol Obstet Invest 82: 105-112, 2017.

69. Tobiume T, Kotani Y, Takaya H, Nakai H, Tsuji I, Suzuki A and Mandai M: Determinant factors of postoperative recurrence of endometriosis: Difference between endometrioma and pain. Eur J Obstet Gynecol Reprod Biol 205: 54-59, 2016.

70. Lin K, Zhan H, Ma J, Xu K, Wu R, Zhou C and Lin J: Silencing of SRA1 regulates ER expression and attenuates the growth of stromal cells in ovarian endometriosis. Reprod Sci 24: 836-843, 2017. 
71. Ohara F, Abdala-Ribeiro HS, Rodrigues FC, Aldrighi JM and Ribeiro PA: Outcomes of laparoscopic treatment of rectosigmoid endometriosis: The linear nodulectomy and the segmental ressection. J Minim Invasive Gynecol 22: S95, 2015.

72. Seyhan A, Ata B and Uncu G: The impact of endometriosis and its treatment on ovarian reserve. Semin Reprod Med 33: 422-428, 2015.

73. Gashaw I, Stiller S, Böing C, Kimmig R and Winterhager E: Premenstrual regulation of the pro-angiogenic factor CYR61 in human endometrium. Endocrinology 149: 2261-2269, 2008.

74. Yanokura M, Banno K, Iida M, Irie H, Umene K, Masuda K, Kobayashi Y, Tominaga E and Aoki D: MicroRNAS in endometrial cancer: Recent advances and potential clinical applications. EXCLI J 14: 190-198, 2015.

75. Widodo Djati MS and Rifa'i M: Role of MicroRNAs in carcinogenesis that potential for biomarker of endometrial cancer. Ann Med Surg (Lond) 7: 9-13, 2016.

76. Witek Ł, Janikowski T, Bodzek P, Olejek A and Mazurek U: Expression of tumor suppressor genes related to the cell cycle in endometrial cancer patients. Adv Med Sci 61: 317-324, 2016.
77. Parkin DM, Bray F, Ferlay J and Pisani P: Estimating the world cancer burden: Globocan 2000. Int J Cancer 94: 153-156, 2001.

78. Long Roche K, Angarita AM, Cristello A, Lippitt M, Haider AH, Bowie JV, Fader AN and Tergas AI: 'Little big things': A qualitative study of ovarian cancer survivors and their experiences with the health care system. J Oncol Pract 12: e974-e980, 2016.

79. Yokoyama Y, Futagami M, Watanabe J, Sato N, Terada Y, Miura F, Sugiyama T, Takano T, Yaegashi N, Kojimahara T, et al: Redistribution of resistance and sensitivity to platinum during the observation period following treatment of epithelial ovarian cancer. Mol Clin Oncol 2: 212-218, 2014.

This work is licensed under a Creative Commons Attribution-NonCommercial-NoDerivatives 4.0 International (CC BY-NC-ND 4.0) License. 